\title{
UMA TESSITURA SOBRE RELAÇÕES TEMPORAIS E ESPACIAIS EM PRÁTICAS CULTURAIS (ESCOLARES) QUE REVERBERAM EFEITOS NO CURRÍCULO
}

\author{
A "TESSITURA" ABOUT TIME AND SPACE RELATIONS IN (SCHOLAR) CULTURAL \\ PRACTICES THAT REVERBERATE EFFECTS IN THE CURRICULUM
}

\author{
UNA TESITURA SOBRE LAS RELACIONES TEMPORALES Y ESPACIALES EN LAS \\ PRÁCTICAS CULTURALES (ESCOLARES) \\ QUE REVERBERAN LOS EFECTOS EN EL CURRÍCULUM
}

Juciara Guimarães Carvalho'; Jackeline Rodrigues Mendes²

\begin{abstract}
RESUMO
Esse texto, uma parte de um trabalho de tese em andamento, pretende mover uma rede de sentidos em torno de temporalidades e espacialidades em práticas culturais (escolares) e suas possíveis reverberações no currículo. Para tecer essa rede, a trama investigativa acontece a partir da terapia-gramatical, entendida como problematização indisciplinar (MIGUEL, 2015), que visa rastrear diferentes práticas culturais envolvendo tempo e espaço presente nas formas de vida e, de modo específico, na forma de vida escolar. A problematização se insere nos nossos usos cotidianos de fazer escola na escola e, consequentemente, na educação matemática escolar. Nesse sentido, a mola propulsora da discussão se aproxima da Etnomatemática, na perspectiva da contraconduta, como sendo um agente disparador de modos de condução que estão presentes nas relações temporais e espaciais nos diferentes campos de atividade humana. Trata-se de percorrer diferentes usos das noções de tempo e espaço a partir de atravessamentos filosóficos que podem desconstruir a universalidade dessas noções em nossas práticas. Para tanto, recorremos aos pensamentos dos filósofos Wittgenstein, das Investigações Filosóficas, com a perspectiva da terapia-gramatical e de Foucault com as problematizações sobre o tempo de vida dos homens e os modos de produção de subjetividade. São ferramentas que permitem fazer proliferar a multiplicidade e recusar qualquer relação dicotômica, dogmática e metafísica.
\end{abstract}

PALAVRAS-CHAVE: Educação Matemática. Etnomatemática. Terapia-gramatical. Contraconduta.

\footnotetext{
${ }^{1}$ Doutoranda em Educação - Faculdade de Educação da Universidade Estadual de Campinas (Unicamp). Doutorado-sanduíche - Université Paris 8 Vincennes-Saint-Denis - CAPES/COFECUB. Mestre em Educação Científica e Tecnológica - Universidade Federal de Santa Catarina (UFSC). E-mail: juciaragcarvalho@gmail.com ${ }^{2}$ Doutorado em Lingüística Aplicada - Universidade Estadual de Campinas. Professor doutor - Faculdade de Educação, Universidade Estadual de Campinas. E-mail: ndanda10@gmail.com

Submetido em: 09/10/2019 - Aceito em: 10/01/2020
}

(C) ETD-Educação Temática Digital Campinas, SP $\quad$ v.23 n.1 p. 231-249 jan./mar.2021




\section{ABSTRACT}

This text intends to move a mesh of meanings around temporalities and spatialities in cultural (school) practices and their possible reverberations in the curriculum. To weave this mesh, the investigative plot takes place from grammatical therapy, understood as undisciplinary problematization (MIGUEL, 2015), which aims to track different cultural practices involving time and space present in life forms and, specifically, in the school life form. The problematization is part of our daily uses of doing school in school and, consequently, in school mathematics education. In this sense, the driving force of the discussion approaches Ethnomathematics, from the perspective of the counter-conduct, as a triggering agent of driving modes that are present in temporal and spatial relations in different fields of human activity. It is about going through different uses of the notions of time and space from philosophical crossings that can deconstruct the universality of these notions in our practices. Thus, we resort to the thoughts of philosophers Wittgenstein, the Philosophical Investigations, with the perspective of grammatical therapy and Foucault with the problematizations about the life span of men and the modes of production of subjectivity. They are tools that allow multiplicity to proliferate and refuse any dichotomous, dogmatic and metaphysical relationship.

KEYWORDS: Mathematical Education. Ethnomathematics. Grammar therapy. Counter-conduct.

\section{RESUMEN}

Este texto tiene la intención de mover una red de significados en torno a las temporalidades y espacialidades en las prácticas culturales (escolares) y sus posibles reverberaciones en el plan de estudios. Para tejer esta red, la trama de investigación se lleva a cabo a partir de la terapia gramatical, entendida como problematización indisciplinar (MIGUEL, 2015), que tiene como objetivo rastrear diferentes prácticas culturales que involucran el tiempo y el espacio presente en formas de vida $y$, específicamente, en forma de vida escolar. La problematización es parte de nuestros usos diarios de hacer la escuela en la escuela y, en consecuencia, en la educación matemática escolar. En este sentido, la fuerza impulsora de la discusión se acerca a la Etnomatemática, desde la perspectiva de la contraconducta, como un agente desencadenante de los modos de conducción que están presentes en las relaciones temporales y espaciales en diferentes campos de la actividad humana. Se trata de pasar por diferentes usos de las nociones de tiempo y espacio a partir de cruces filosóficos que pueden deconstruir la universalidad de estas nociones en nuestras prácticas. Para este fin, recurrimos a los pensamientos de los filósofos Wittgenstein, las Investigaciones filosóficas, con la perspectiva de la terapia gramatical y Foucault con las problematizaciones sobre la vida de los hombres y los modos de producción de subjetividad. Son herramientas que permiten que la multiplicidad prolifere y rechace cualquier relación dicotómica, dogmática y metafísica.

PALAVRAS-CLAVE: Educación Matemática. Etnomatemática. Terapia-gramatical. Contra conducta.

\section{NO RASTRO DE NOSSOS USOS COTIDIANOS...}

Não se trata de uma explicação de um jogo de linguagem através de nossas vivências, mas da constatação de um jogo de linguagem (WITTGENSTEIN, 2014, $\S 655$, p. 223).

Ao considerar a perspectiva wittgensteniana de uma investigação terapêutica submetemos as noções de tempo e espaço a uma terapia-gramatical com o propósito de rastrear os diferentes usos cotidianos que temos praticados na Educação Matemática e, em particular, os modos de vivenciar o tempo e habitar o espaço presentes nas práticas culturais que reverberam efeitos no currículo escolar. Em outras palavras, trata-se de ampliar os modos de se relacionar com o tempo e o espaço, a educação matemática escolar e o currículo que os regula e os disciplinariza. A terapia-gramatical, assim praticada por Miguel, Vilela e Moura (2012, p.14), tem como propósito "fazer um conceito, enunciado ou

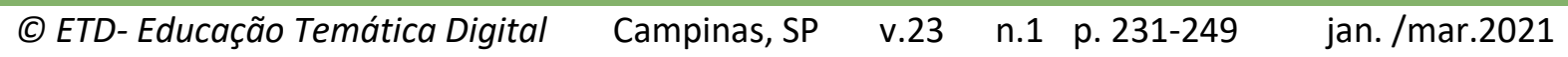


uma prática cultural deslocar-se de um campo a outro de atividade humana a fim de se pôr em evidência significações distintas que pode ser produzidas para esse conceito, enunciado ou prática cultural".

Nesse movimento de percorrer diversos usos nos diferentes jogos de linguagem, pretendemos multiplicar os sentidos ao tecer uma trama, um tecido, a partir de fios e nós de sentidos em torno das temporalidades e espaços. Trata-se de percorrer os usos que orientam nossas práticas culturais, sociais, éticas e políticas, visando "desfazer imagens exclusivistas, isto é, aquelas que alimentamos e por isso parecem eternas e que não podem ser de outro modo" (MIGUEL, VILELA e MOURA, 2012, p. 11). Podemos considerar que "a terapia-gramatical luta contra o mau uso das palavras, isto é, contra o essencialismo e o dogmatismo" (ibidem, p. 15). Desse modo, essa perspectiva filosófica amplia o campo de visão para os diferentes campos de atividade humana e dispersa os usos dominantes ao descrever os "diversos usos, olhar como se designam as coisas em diferentes situações na prática da linguagem, olhar para suas diferentes aplicações, efetivas, possíveis, e mesmo inusitadas" (ibidem, p.10). Assim, a atitude terapêutica-gramatical possibilita um movimento que orienta essas ações de modo a mudar o olhar para com as práticas escolares, as investigações acadêmicas e os modos de vida.

Contudo, nas palavras de Miguel (2015, p. 638), "ela não pode ser vista ou praticada como um método mecânico, homogêneo e estruturado de produção ou validação da produção de significados em qualquer domínio - formal ou informal -, dado que ela não é uma atitude dotada do poder de se autolegitimar a si própria". Afinal, o propósito de uma investigação terapêutica-gramatical é o de constituir investigadores de si, pois realizar a terapia, não deixa de ser também uma autoterapia (MIGUEL, 2015). Esse posicionamento possibilita pensar a terapia-gramatical como sendo uma problematização indisciplinar, como praticada por Miguel, Vilela e Moura (2012), que intenciona abrir a escola aos diferentes campos de atividade humana, não como uma simples oposição ao princípio disciplinar, mas para problematizar as diferentes formas de vida, considerando as práticas de democratização social, política e econômica. O verbo problematizar intenciona "discutir, questionar e avaliar todos os tipos de relações assimétricas de poder que se instauram em quaisquer comunidades humanas" (ibidem, p.8). 
Esse momento, especificamente, requer uma problematização indisciplinar que objetiva rastrear diferentes práticas culturais envolvendo tempo e espaço presentes nas formas de vida e, de modo específico, na forma de vida escolar, tanto no contexto da educação escolar quanto na formação de professores. Trata-se de percorrer diferentes usos das noções de tempo e espaço a partir de atravessamentos filosóficos que podem desconstruir a universalidade dessas noções em nossas práticas e nas implicações curriculares. O currículo atravessa a Educação Matemática na medida em que "opera a distribuição dos saberes - pondo-os e dispondo-os, hierarquizando-os, matizando-os e classificando-os, atribuindo-lhes valores -, ele estabelece o fundo para que tudo o mais (no mundo) seja entendido geometricamente" (VEIGA-NETO, 2002, p.165). Nesse sentido, o currículo, como sendo um artefato escolar que foi produzido por uma forma dominante, eurocêntrica, de pensar as coisas do mundo, é também produtor da mesma.

Em outras palavras, o currículo, ao ser pensado e posto em funcionamento a partir de uma lógica classificatória e disciplinar, atua, nas palavras de Veiga-Neto (2002, p. 171), como um estruturante disciplinador. $\mathrm{O}$ autor salienta que a própria palavra disciplina tanto se refere ao campo dos saberes quanto a uma maneira de 'estar no mundo'. Isso implica que o currículo produz e é produtor de subjetividade e, portanto, assujeita indivíduos, tornando-os sujeitos escolares pela geometria do currículo que constitui a malha do tempo e do espaço escolar. Fato este que implica diretamente na constituição das relações temporais e espaciais que estabelecemos nas formas de vida escolares. Um tempo estritamente medido, calculado, determinado antes mesmo de ser vivido e um espaço estriado, quadriculado, que disciplinariza os corpos. Nossas vidas escolares estão tão geometrizadas que parecem estar todas desenroladas antes mesmo de serem vividas, pois temos um tempo e um espaço determinados para que as coisas aconteçam e como elas devem acontecer.

No campo da Matemática e da Educação Matemática, consideramos no compasso dessa discussão que a Etnomatemática, entendida como um movimento de 'contraconduta' no interior desses campos, impulsionou problematizações sobre os diferentes modos de vivenciar os tempos e de habitar os espaços nos diferentes campos de atividade humana, e também trouxe implicações para pensar a questão dos saberes no currículo (Monteiro e Mendes, 2015; 2019). A perspectiva etnomatemática possibilitou a abertura de caminhos para uma prática indisciplinar que problematiza os usos que praticamos na matemática escolar e na educação matemática escolar, ou, ainda, gerou visibilidade para que o nosso fazer escola na escola possa trilhar por caminhos indisciplinares. Segundo Knijnik et.al. (2012), a Etnomatemática segue interessada em discutir a política do conhecimento dominante praticada na escola, isto é, permite problematizar os discursos eurocêntricos que instituem as matemáticas acadêmica e escolar; analisar os efeitos de verdade produzidos

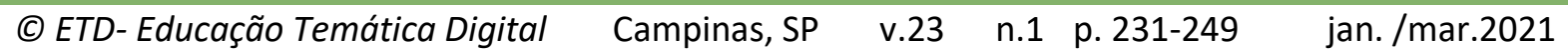


pelos discursos das matemáticas acadêmica e escolar; discutir questões da diferença na educação matemática, considerando a centralidade da cultura e as relações de poder que a instituem; e examinar os jogos de linguagem que constituem as diferentes matemáticas e suas semelhanças de família.

No entanto, cabe um cuidado no que diz respeito à polissemia da perspectiva etnomatemática, portanto, insere-se a necessidade de problematizá-la em seus usos e possibilitar a ela espaços outros de produção. Desde seu surgimento, na década de 1970, um vasto número de educadores (as) matemáticos (as), no país e também no exterior, tem desenvolvido estudos etnomatemáticos que dão continuidade e que produzem deslocamentos, sendo inicialmente concebidos por D' Ambrosio (KNIJNIK et. al., 2012). Assim, consideramos que, ao perguntar $\mathrm{O}$ que é a Etnomatemática? na tentativa de explicar e definir "o que é", criou-se a necessidade de encontrar sua essência pautada no discurso da metafísica capaz de fornecer um fundamento a todas as coisas, revelar sua natureza e delimitação. No entanto, essa pergunta coloca-nos em uma armadilha, pois, "ao buscar estabelecer conexões com algo que é, nos afastamos das possibilidades, das inquietudes, do desconhecido" (MONTEIRO; MENDES, 2015). O problema está no fato de que a emergência da Etnomatemática está relacionada com a metanarrativa, a estrutura que constitui a Matemática Acadêmica. Isso implica o desejo de responder O que é a Etnomatemática?. Fica-se preso ao próprio labirinto que se criou. "A Etnomatemática não é, ela está sendo, ela é uma formação discursiva em movimento" (ibidem, p. 7).

Bello e Longo (2010) chamam a atenção para a necessidade de uma compreensão dos regimes de verdade, da produção de saberes e das relações de poder que se estabelecem no discurso presente nas diferentes perspectivas etnomatemáticas. Isso demanda "explorá-la nos seus usos, nos diferentes discursos produzidos e estabelecidos como verdadeiros que designam enunciados e nas suas práticas que obedecem a regras de funcionamento" (ibidem, p. 8). Assim, discutir a Etnomatemática requer problematizá-la observando sua multiplicidade, antagonismos e paradoxos, já que ela se apresenta como uma resistência aos modos de governamento (im)postos pelo campo da matemática formal, uma resistência que não nega a matemática, mas busca novas formas de pensar esse saber, novas condutas e normas de constituição desse saber (MONTEIRO; MENDES, 2015; 2019). Ao considerar a Etnomatemática como um movimento de 'contraconduta', possibilita-se também "denunciar e modificar os dispositivos que sustentam as relações que permeiam os processos de validação e legitimação do saber escolar" (ibidem, p. 8). 
Afinal, a Etnomatemática emergiu como um movimento de 'contraconduta' no interior do campo de saber da Matemática Acadêmica. O termo 'contraconduta' é empregado no sentido de "luta contra os procedimentos postos em prática para conduzir os outros" (FOUCAULT, 2008, p.271). Já a palavra 'conduta', para Foucault (2008), é ambígua, visto se referir a duas coisas: à prática de condução e também à maneira como uma pessoa se deixa conduzir, o que nos remete à ideia de conduta como movimento no qual o sujeito tem a possibilidade de querer ser conduzido de outra forma. De um lado, o cuidado reside em fazer da 'contraconduta' um modo de resistência e não uma nova conduta, modo de conduzir que seja capturada. O imperativo é o movimento transgressivo que escapa da calmaria condutora. Do outro lado, a crítica, no que diz respeito à Etnomatemática, persiste quando há "um reforço do modelo universalista e totalitário, especialmente quando a diferença é pensada como modo de superação ou de uma comparação, a qual tem como referência a Matemática acadêmica, e não como uma diferença em si mesma" (MONTEIRO; MENDES, 2019, p.9).

Diante desse posicionamento e do esforço em ampliar a discussão da politicidade do conhecimento, faremos usos das ferramentas filosóficas para problematizar os saberes institucionalizados pelo currículo que produzem subjetividade, assujeitamento e forma as formas de vida nas tramas de um pensamento dominante e universal. Para tanto, traçamos um diálogo teórico-metodológico a partir do pensamento dos filósofos Wittgenstein, em sua segunda fase, com a terapia-gramatical e a noção de jogos de linguagem; e Foucault, a partir da problematização sobre o tempo de vida dos homens e os modos de produção subjetividade. Embora Wittgenstein e Foucault estejam situados em problemáticas distintas, em época diferentes, ambos os filósofos inspiram-nos a intervir por reverberações que nos coloquem de volta ao "chão áspero" para problematizar os usos praticados em nossas formas de vida, mais especificamente na Educação Matemática, nas formas de vida escolares.

Consideramos vital evidenciar como as diferentes formas de vida nos ensinam a perceber o tempo e o espaço de modos diferentes em suas práticas culturais. As relações temporais e espaciais produzidas nesses distintos lugares constituem outros usos e produções de significados atrelados ao seus jogos de linguagem, em sua gramática. Isso implica na criação um modo outro de pensar-agir e estar no mundo que escapa da rigidez dos ponteiros, da estriagem restrita e se recusa a dobrar-se nas formas de produção dominantes e universalizantes. Carvalho (2016), em sua pesquisa, percorre jogos de linguagem na forma de vida de pescadores artesanais envolvendo tempo e espaço. Nesses movimentos de perceber os usos e sentidos em torno tempo e espaço, identifica que

A obrigação de viver e sentir o "agora", o acontecimento que nos impossibilita saltar o intervalo de tempo é a mesma que nos faz parar e habitar o "aqui" e

(C) ETD-Educação Temática Digital Campinas, SP $\quad$ v.23 $\quad$ n.1 $\quad$ p. 231-249 jan./mar.2021


habitar um espaço para deixar-se ficar. Foi nas águas de cada mar-lagoa que aprendi que um espaço pode ser ocupado sem ser medido, sendo constituído por acontecimento, espera, desejo, olhar, gesto, sorriso, silêncio e fala. Os Camaradas D'água vivem um tempo e habitam um espaço que enunciam saberes a partir/com os olhos, o espírito e o corpo todo, estão situados no "aqui e agora" com os "aqui" e os "agora" sempre em vias de atualizar-se. (CARVALHO, 2016, p. 159-160)

A unidade temporal e a espacial são percebidas, portanto, na certeza da incerteza e a precisão da imprecisão que desnudam o tempo e espaço.

Dito de outra maneira, desejamos realizar um exercício sensível provocado por Monteiro e Mendes (2014) para pensar e indagar sobre: quais são as vozes e culturas silenciadas nos tempos e espaços escolares? De que forma possibilitar emergências, existências e visibilidades dessas vozes, esgarçando o tecido estriado desses tempos e espaços? Como promover no espaço escolar um ambiente democrático, possibilitando o confronto e o diálogo entre subjetividades? Segundo as autoras, o uso atribuído ao diálogo refere-se não como caminho da síntese, do consenso, mas como uma potencialidade em sua linha tensional. Ou ainda, especificamente, podemos perguntar que tempos e espaços são silenciados? Afinal, mesmo que essas noções sofram metamorfoses, ainda apresentam elementos que são reguladores sociais, culturais e políticos que constituíram e constituem os modos de pensar, agir e habitar o mundo. Nesse sentido, recorreremos aos atravessamentos filosóficos que desconstroem as noções naturalizadas de tempo e espaço da vida (escolar). O que se requer é um ritmo andante que possibilite um tempo de parada, uma desaceleração e exige-se um contraespaço para trilhar caminhos indisciplinares. Para encenar esse movimento, propomos a articulação entre os pensamentos de Wittgenstein e Foucault, de modo a potencializar a criação de movimentos outros e fazer da prática filosófica um modo de vida.

\section{TRILHANDO PELA DIFERENÇA...}

Qual é o seu objetivo na filosofia? - Mostrar à mosca a saída da apanha-moscas (WITTGENSTEIN, 2014, §309, p.141).

'O que acontece atualmente e o que somos nós, nós que talvez não sejamos nada mais e nada além daquilo que acontece atualmente?' A questão da filosofia é a questão deste presente que é o que somos (FOUCAULT, 2005, p. 239).

Nesse momento percorreremos algumas pistas de possíveis aproximações pela diferença do pensamento wittgensteniano e foucaultiano, pelas dissonâncias que se encontram em ressonância e que potencializam praticar a filosofia como um modo de vida. Afinal, a tarefa filosófica consiste em assumir uma atitude, um ethos, que é ao mesmo tempo ética e política da transformação de si mesmo, dos outros e do mundo. Em outras palavras, a intenção não é traçar a convergência do pensamento de ambos os filósofos e nem mesmo contrapô-los com o costume teórico-metodológico tradicional, mas fazer com

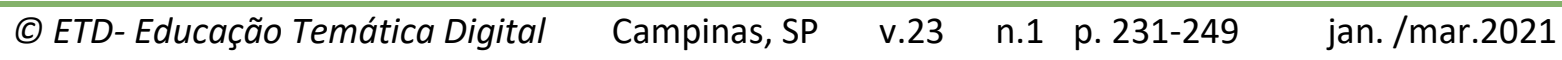


que seus modos de praticar a filosofia possam funcionar em diálogo e nos ofereça algo para pensar, problematizar e reproblematizar aquilo que nos move. É fazer usos de suas ferramentas filosóficas para repensar a educação contemporânea como sendo uma grande "instituição" que produz subjetividade, assujeitamento e forma as formas de vida a partir do fio condutor do tempo e da disciplinarização dos corpos no espaço.

Wittgenstein e Foucault, mesmo estando situados em problemáticas distintas, inspiram-nos a intervir por reverberações que nos coloquem de volta ao "chão áspero" para problematizar os usos praticados em nossas formas de vida. Segundo Gros e Davidson (2011, p. 7), "podemos encontrar de um para o outro não declarações comuns, mas posturas comuns" 3 . Acrescenta dizendo que "quer a compreendamos como uma visão do mundo, quer como uma técnica de cuidado da alma, a ética para Foucault e Wittgenstein, não é a moral" (ibidem, p.7). Nesse viés, tanto em Wittgenstein como em Foucault podemos encontrar "uma valorização decisiva da coragem como raiz ética da verdade" ${ }^{4}$. Inspirados nessa coragem, o mais difícil está por vir: "fazer ressoar os dois pensamentos ao nível de uma descrição geral dos enunciados e de uma sistemática do discurso, sempre ligadas a esta problemática de nós mesmos"5 (GROS; DAVIDSON, 2011, p. 8).

Ambos os filósofos, cada um a sua maneira, rompem com o modelo de racionalidade da modernidade ao realizarem diversas problematizações acerca dos modelos tradicionais da filosofia, envolvendo questões epistemológicas, éticas, estéticas e política, ao mesmo tempo em que desencadearam um processo de desconstrução da própria filosofia. Os encontros ou até mesmo as confrontações estabelecidas entre o pensamento de Wittgenstein e Foucault somente se tornam possíveis "através da descoberta de uma preocupação em comum a esses dois autores, a saber, a recusa do psicologismo e o questionamento do que poderíamos chamar de uma filosofia da consciência"6 (GILLOT; LORENZINI; 2016, p.12). Eles nos oferecem um modo despsicologizante da filosofia como possibilidade de extrapolar os entendimentos sobre a subjetividade, inserindo a questão de uma subjetividade sem sujeito. A crítica, segundo Gillot e Lorenzini (2016), está na noção

\footnotetext{
3 [Versão original]: C'est ainsi qu'on peut retrouver de l'um à l'autre, non pas des énoncés communs, mais des postures communes. (...) Qu'on la comprenne soit comme une vision du monde, soit comme une tecnique de soin de l'âme, l'éthique pour Foucault et Wittgenstein, ce n'est pas la morale.

${ }^{4}$ [Versão original]: Surtout on trouve, chez Wittgenstein et Foucault, une valorisation décisive du courage comme racine éthique de la verité.

${ }^{5}$ [Versão original]: Mais le plus difficile restait à faire, ce qu'on entrepris de jeunes philosophes qui avaient travaillé tout à la fois sur Wittgenstein et Foucault: faire résonner les deux pensées au niveau d'une description générale des énoncés et d'une systématique discours, toujoursliées à cette problematiion de nous-même.

${ }^{6}$ [Versão original]: Mais cette confrontation n'est elle-même rendue possible que grâce à la mise au jour d'une préocupation théorique fondamentale commune à ces deux auteurs, à savoir le refus du psychologisme et la mise en question de ce que l'on a pu appeler une <<philosophie de la conscience〉> .
}

(C) ETD-Educação Temática Digital Campinas, SP $\quad$ v.23 $\quad$ n.1 $\quad$ p. 231-249 jan./mar.2021 
clássica de subjetividade soberana [cartesiana] como modelo que conduz um sujeito de ação e de conhecimento transparente a si mesmo.

A prática filosófica wittgensteniana e a foucaultiana "dão as costas para a busca de uma suposta razão pura e voltam-se para a análise das relações da linguagem consigo mesma e das relações entre a linguagem e o mundo" (VEIGA-NETO, 2011, p.90-91). Em efeito, é possível afirmar que o processo de constituição do sujeito acontece na e pela linguagem. Nessa perspectiva, a linguagem possui um caráter não representacional, ou seja, não há uma linguagem por trás de outra linguagem que carregue consigo uma essência. Há apenas o que é dito e constituído pelas formações históricas, políticas, sociais e culturais e que oferece as 'condições de possibilidade' para dizer e compreender sobre as coisas do mundo. Contudo, Bello chama a atenção para o fato de que

não se pretende assumir a linguagem numa perspectiva totalizadora ou de princípio fundamental e único de inteligibilidade, mas desconstruí-la como mediação privilegiada entre nós e o mundo; assumi-la como uma das condições de possibilidade e de existência das formas de vida, do mundo, das subjetividades. (BELLO, 2010, p. 550-551)

Nesse sentido, pode-se afirmar a existência de diferentes processos de subjetivação em conformidade com as diferentes formas de vida.

A partir desse posicionamento sobre a linguagem, a qual abarca sua condição de pluralidade, multiplicidade, já que estamos falando de práticas e de usos, podemos considerar esses usos como produtores de significação, sem perder de vista que eles estão imbricados e indissociados em cada forma de vida, com suas regulações éticas e políticas, ou seja, participam de diferentes jogos de linguagem que abrangem não apenas a linguagem, mas também as atividades com as quais ela vem entrelaçada (WITTGENSTEIN, 2014, §7, p. 19). Os jogos de linguagem não funcionam por uma unicidade, universalidade e essência das formas de conhecimento, funcionam pela multiplicidade que prolifera no cotidiano movente das formas de vida pelo fio de suas gramáticas de funcionamento. Ademais, “(...) nós conduzimos as palavras do seu emprego metafísico de volta ao seu emprego cotidiano" (WITTGENSTEIN, 2014, §116, p. 72). Isso ocorre pelo fato de que "a linguagem assume uma característica contingente, interessa agora explorar as propriedades do fenômeno, suas características, o seu funcionamento, a sua utilidade, sua operação" (BELLO, 2010, p.553).

$\mathrm{Na}$ leitura foucaultiana, o discurso é considerado pelas práticas que formam sistematicamente os objetos de que falam. Trata-se de "mostrar como práticas sociais podem gerar domínios de saber que, além de formar objetos, conceitos, técnicas, têm constituído sempre formas de ser sujeito" (BELLO, 2010, p.561). Criam-se, portanto, jogos estratégicos, em aproximação com a expressão wittgensteniana de jogos de linguagem, "constituintes das práticas sociais constituem, para um espaço-tempo específico, os sujeitos

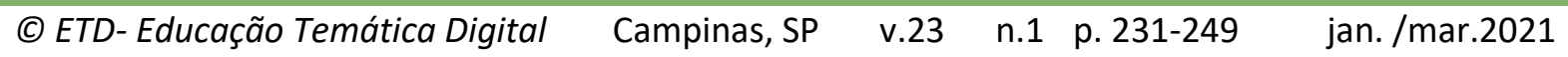


de conhecimento" (ibidem, p.561). Tal jogo possibilita evidenciar os modos de condução que se têm praticado, assim como interrogar, pelas regras e regulações que são colocadas a operar no nosso modo de viver no mundo. No caso aqui proposto, podemos perguntar sobre o funcionamento da produção de subjetividade e das relações temporais e espaciais que nos constituíram e constituem como sujeitos modernos e sobre os modos de assujeitamento considerando, notadamente, o campo da educação matemática.

Para tecer desdobramentos de uma problematização indisciplinar do presente para e na educação contemporânea, é necessário buscar 'condições de possibilidade' outras para composições ou im(composições) impensáveis. Isso implica na afirmação de outras gramáticas, no plural, como sendo um conjunto complexo de regras que são acionadas como 'condições de sentido' ou 'sistemas de significados' em diferentes formas de vida. Significa dizer que as descrições gramaticais, que percorrem os diversos usos de um conceito na prática linguística e na não-linguística, permitem descrever o funcionamento das ações das formas de vida e os modos como são reguladas pelos jogos de linguagem. A implicação direta é a negação de uma 'inclusão excludente' de saberes que habitam superficialmente o currículo. Trata-se de intervir por um curriculum que "implica uma ação necessariamente temporal - que se desenvolve num espaço" (VEIGA-NETO, 2002, p.171).

Podemos encontrar na filosofia de Foucault algumas práticas que encenam como o tempo e o espaço são variáveis de análise presentes no sistema do poder capitalista e no sistema penal e como elas reverberam seus efeitos na constituição do currículo escolar. São práticas que evidenciam como as gramáticas do tempo e do espaço foram e ainda são colocadas a operar na sociedade de modo a regular os corpos. O poder e a verdade do tique-taque, ao passo que os meios de manifestação da verdade do tempo operam com o 'tempo panóptico', em forma de vigilância, controle, recompensa e punição. A verdade do tempo captura o tempo de vida dos homens e funciona como se a vida já estivesse toda desenrolada. E com ele, toda a maquinaria capitalística é acionada, na qual "já não se pune por meio do corpo, dos bens, mas pelo tempo por viver" (FOUCAULT, 2015, p. 66). Essa maquinaria funciona a partir de um único relógio, cujos ponteiros percorrem o maior número de corpos e ações, pois "vivemos hoje uma sociedade programada" (FOUCAULT, 2013, p. 103). Somos governados pela verdade do tempo operando em todos os espaços sob os processos de subjetivação que regulam a vida do tempo e que causam o sentimento da falta, a falta de tempo.

A captura do tempo é ilustrada por Foucault (2013, p.114) ao evidenciar as instituições de sequestro, constituídas na sociedade industrial moderna, que "têm a propriedade muito curiosa de implicarem o controle, a responsabilidade sobre a totalidade, ou a quase totalidade do tempo dos indivíduos; são, portanto, instituições que, de certa forma, se encarregam de toda dimensão temporal da vida dos indivíduos". Foucault cita

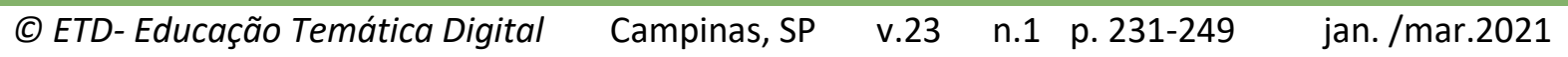


como exemplo instituições com os mesmos princípios de funcionamento: escolas, orfanatos, centros de formação, prisão, fábrica, casa de recuperação, hospitais e asilos. "É preciso tomar o poder sobre o tempo, não como uma abstração ideológica, mas como extração real do tempo da vida dos homens: condição real de possibilidade do funcionamento do sistema de salário e do sistema de reclusão" (FOUCAULT, 2015, p. 78). Trata-se de "fixar os indivíduos em um aparelho de normalização dos homens" (FOUCAULT, 2013, p. 113) implicado na relação entre o exercício de poder e a manifestação da verdade. Uma ordem pura da verdade é instituída: o tempo de vida dos homens é transformado no tempo de trabalho (tempo de produção).

A sociedade moderna aprisiona nossa existência, uma vez que não se interessa pelo controle espacial dos indivíduos, interessa-se pela extração da totalidade do tempo da existência humana. Nas palavras de Foucault:

por um lado, o tempo da vida torna-se matéria permutável; por outro, a medida do tempo é que possibilita a quantificação da troca, por meio da relação estabelecida entre uma quantidade de trabalho e uma quantidade de dinheiro, ou então entre uma quantidade de tempo e a gravidade da culpa. (FOUCAULT, 2015, p. 78)

Essa percepção mostra os usos que fazemos do tempo de vida dos homens e da vida do tempo, o funcionamento da não-vida dos homens. As instituições têm por finalidade não excluir, mas fixar os indivíduos nos processos de subjetivação da qual participam em conformidade com suas normas; a fábrica liga os indivíduos a um aparelho de produção; a escola fixa a um aparelho de transmissão do saber; o hospital psiquiátrico liga-os a um aparelho de correção (FOUCAULT, 2013). E, consequentemente, é enquanto indivíduos que se entra na escola, no hospital ou na prisão, pois a função das instituições é constituir assujeitamentos, processos de subjetivação, de uma coletividade de sujeitos. Um tempo que individualiza a serviço de um grupo de produção.

Ao articular esses agenciamentos, a partir de práticas culturais, é possível fazer reverberar seus efeitos nas relações temporais e espaciais que constituem o currículo. A forma de vida escolar não escapa das "operações de confinamento, quadriculamento, distribuição, atribuição de funções, hierarquização. Em qualquer caso, trata-se sempre de organizar economicamente o espaço e o tempo" (VEIGA-NETO, 2002, p.172). Afinal, ainda operamos de modo disciplinar, tanto no que diz respeito ao currículo quanto às nossas ações, ao quadricular o tempo e o espaço para o acontecimento na educação matemática escolar. Fixamos grades organizadas em disciplinas, focamos no processo de ensino e aprendizagem e não na sua problematização, organizamos calendários, cronogramas, horários escolares, como se a vida escolar já estivesse toda desenrolada, vivida. Nesse sentido, cabe a problematização dos nossos modos de condutas que temos praticado a fim

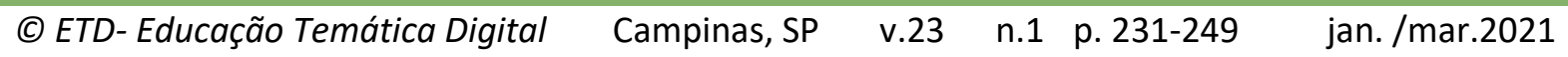


de encontrar 'contracondutas' outras que nos movimente diferentemente e que não recaiam em novas condutas que cristalizam o pensamento.

\title{
3 OUTRAS CENAS: UM TEMPO PARA TORNAR-SE LIVRE...
}

\begin{abstract}
Um tempo e um lugar profanos, mas também as coisas profanas, referem-se a algo que é desligado do uso habitual, não mais sagrado ou ocupado por um significado específico, e, portanto, algo do mundo que é, ao mesmo tempo, acessível a todos e sujeito à (re)apropriação de significado. É algo, nesse sentido geral (não religioso), que foi corrompido ou expropriado; em outras palavras, algo que se tornou público. (MASSCHELEIN; SIMONS, 2013, p. 39)
\end{abstract}

Diante dessa profanação, queremos problematizar as relações de saber-poder, de um tempo e um espaço hegemônicos e da necessidade de discutir sobre o do cuidado de si, temporal e espacial, indispensável para o campo da Educação Matemática. Assim, intervimos por um tempo que seja nosso e que ele faça pulsar outras gramáticas que habitam as diferentes formas de vida. Vidas que, diante de suas práticas culturais, inventam outras formas de perceber o tempo e de habitar o espaço e, portanto, potencializam a reflexão sobre os usos que fazemos do tempo diante de nossas práticas cotidianas ou das instituições de sequestro. Isso afeta o próprio olhar para com as práticas matemáticas escolares, pois "aprender matemática, nesse sentido, é compartilhar significados em diversos usos, penetrar nos diferentes jogos de linguagem" (MIGUEL; VILELA \& MOURA, 2012 , p.10). A partir desse cenário, interrogamos pelo tempo de vida (escolar) que se insere no projeto de escolarização moderna: a transformação do tempo de vida em tempo de produção. Uma instituição que se constitui a partir de uma disciplina geral da existência funcionando como produtora de processos de subjetivação.

As noções de tempo e espaço são invisibilizadas pelas práticas capitalísticas ao ponto de se tornarem inquestionáveis no campo educacional escolar e inabaláveis em termos de currículo. Em outras palavras, "o currículo imprimiu uma ordem geométrica, reticular e disciplinar, tanto aos saberes quanto à distribuição desses saberes ao longo de um tempo" (VEIGA-NETO, 2002, p.164). Isso implicou em determinar uma única forma para as coisas acontecerem no tempo e no espaço. Por outro lado, temos como resistência a possibilidade de constituir 'contracondutas' curriculares que escapem da captura de novas condutas e funcionem na potencialidade de seus usos e criações sempre moventes. Cabe tatear condutas vivenciadas pela forma de vida escolar e como seus efeitos produziram subjetividade para, então, transgredir na produção de 'contracondutas' que permitam que tempos e espaços outros silenciados pelas relações curriculares ocupem lugares de "fala". 
Desde o início, nas cidades-estados gregas, o fazer escola na escola era acoplado aos modos de viver o tempo, uma relação que se estabelece a partir de skholé, que significa "tempo livre, descanso, adiamento, estudo, discussão, classe, escola, lugar de ensino" (MASSCHELEIN; SIMONS, 2013, p.25). Realizando uma breve digressão sobre a relação escola e tempo livre é possível perceber nuances e deslocamentos dos usos do tempo nas vidas escolares. Primeiramente, "a escola fornecia tempo livre, isto é, tempo não produtivo, para aqueles que por seu nascimento e seu lugar na sociedade (sua posição) não tinham direito legítimo de reivindicá-lo" (ibidem, p. 26). A invenção do escolar estabelecia um tempo e espaço separado, em certo sentido, da sociedade e da família com o propósito de fornecer um tempo igualitário, sendo a democratização do tempo livre (MASSCHELEIN; SIMONS, 2013). Um tempo livre não entendido como nos dias atuais como tempo de relaxamento ou de lazer, mas como a forma pelo qual os alunos poderiam ser retirados de sua posição social e que permitiria se desconectarem do tempo ocupado pela família e da cidade/estado. "Nos é dado tempo para fazê-lo nós mesmos" (ibidem, p.30).

Nesse momento, podemos dizer que "o tempo escolar é o tempo tornado livre e não é tempo produtivo" (ibidem, p. 33). A prática do tempo insere-se em uma gramática que cria brechas no tempo linear, assim, a função escola implica "não só a interrupção temporária do tempo (passado e futuro), mas também a remoção das expectativas, necessidades, papéis e deveres ligados a um determinando espaço fora da escola" (ibidem, p. 37). O encontro do público para com o que é de livre uso e o novo constituiu uma experiência escolar, a partir das relações temporais presentes nos processos de escolarização, que faz abrir o mundo. "O que a escola faz é trazer algo para o jogo, ou fazer alguma coisa no jogo. Isso não significa que a escola não seja séria e não tenha regras" (ibidem, p. 41). Afinal, há sempre algo movente que nos instiga a lidar com alguma coisa e a estar presente para alguma coisa. Uma captura do tempo à sua maneira e intensidade.

Contudo, ao longo da história da escola sempre houve tentativas de domar o tempo escolar. "Os ataques contra a escola derivam de um impulso para tornar o tempo livre fornecido por ela novamente produtivo e, desse modo, impedir a função de democratização e equalização da escola" (MASSCHELEIN; SIMONS, 2013, p.28). A escola, considerada uma invenção histórica, transforma todos em alunos colocando todos numa situação inicial equivalente. Contudo, esse posicionamento provoca perturbações desde as suas origens. Nesse sentido, "domar a escola implica governar seu caráter democrático, público e renovador. Isso envolve a reapropriação ou a reprivatização do tempo público, do espaço público e do bem comum possibilitados por ela" (ibidem, p. 105-106). Surge a necessidade de governar o tempo e o espaço escolar com o propósito de construir um tempo integralmente útil, tempo produtivo, e de realizar um quadriculamento do espaço. 
Formas de governar essas que, na instituição escolar moderna, são marcadas pela disciplina e pelo controle do corpo (FOUCAULT, 2007). Nasce uma 'anatomia política', calcada em um tempo esquadrinhado com a finalidade de produzir uma 'mecânica do poder', de forma que se tenha um domínio sobre os corpos para que façam não apenas o que ser quer, mas "para que operem como se quer, com as técnicas, segundo a rapidez e a eficácia que se determina" (ibidem, p. 119). Assim, viver o tempo livre modifica-se na modernidade, pois o tempo livre torna-se severamente ocupado pelas manifestações de verdade do currículo escolar, que determina o que/como estudar e para que/quem estudar, ou ainda, os jogos normativos de linguagem que são estabelecidos para orientar as maneiras de pensar e agir nas formas de vida escolares. Um tempo de jogo, um jogo do tempo que produz um tempo produtivo, um tempo clichê.

Se a "herança" do tempo livre transformou-se em tempo de produção, a partir do estriamento do espaço, que é fortemente marcado pela "falta de tempo", de curto prazo e da obsessão pela velocidade, resta-nos indagar o modo como temos nos ocupado, os motivos pelo corre-corre cotidiano e modo de vida que se leva. Esse movimento de inquietação apresenta-se na atualidade das palavras de Sêneca: "reivindica o teu direito sobre ti mesmo e o tempo que até hoje foi levado embora, foi roubado ou fugiu, recolhe e aproveita esse tempo. (...) Mas a coisa mais lamentável é perder tempo por negligência" (SÊNECA, 1991). Isso implica em uma prática de si como atividade crítica em relação a si mesmo, ao mundo, à vida dos outros (FOUCAULT, 2010), ou seja, uma prática tanto individual quanto coletiva que visa transformar-se, modificar-se em seu ser singular. A conhecida encenação socrática: ocupa-te de ti mesmo.

Trata-se de uma questão metodológica do cuidado de si, desenvolvida por Foucault (2010) nos cursos de 1981-1982 no Collège de France, cujo imperativo "cuidar de si mesmo" exige ter tempo, desligar-se, ausentar-se sem sair do lugar. Um cuidado que é ao mesmo tempo consigo mesmo, mas também com os outros. No que diz respeito ao espaço que habitamos e, portanto, ao tempo que vivemos, faz-se necessário desacelerar. Criar 'contracondutas' que possibilitem a problematização de nossas relações temporais e espaciais nas práticas culturais (escolares). Isso porque o cuidado de si

não consiste mais em um conhecimento da alma como parte divina de si, mas o objeto do cuidado é o bios, a vida, a existência, e cuidar de si significa dar forma à própria existência, submeter a própria vida a regras, a uma técnica, a pô-la à prova segundo procedimentos: é a filosofia como arte de vida, técnica de existência, estética de si. (GROS, 2004, p.161) 
É a emergência de condições de existência outras que permite outros modos de vida, porquanto "é-se sempre tomado em uma prática de si e dos outros, e é a mudança dessa prática que produz efeitos de verdade, quer dizer, deslocamentos ou rupturas epistêmicas" (REVEL, 2004, p.86).

A ruptura é entendida como disparadora de outras possibilidades de combinações, arranjos e permutas para a mobilidade do pensamento. Nesse sentido, "a ruptura é, em si mesma, um elemento significante porque marca a história com sua quebra interna, assim como eleva à dignidade do sentido o não linear, o desordenado, o despropósito" (ibidem, p. 70). Desse modo, torna-se pertinente a ruptura das relações temporais e espaciais que nos constituem e que constituímos como potência geradora de outras formas de viver o tempo e habitar o espaço. Em outras palavras, fazer aparecer os tempos e espaços silenciados evidenciando o que neles têm de menor, de força frágil e de liberdade, uma vez que, "pelo simples gesto mínimo que consiste em deslocar o olhar, ele visibiliza o que é invisível, faz aparecer o que está próximo, tão imediato, tão intimamente ligado a nós que, exatamente por isso, não o vemos (...)" (FOUCAULT (1978) apud ARTIÈRES, 2004, p.22). Ou ainda, como diz Wittgenstein $(2014, \S 66$, p. 51): Não pense, mas olhe!

Ao encararmos o desafio faz-se necessário olhar para os pormenores do processo. A saber, fazer pulsar outras gramáticas do tempo e do espaço que podem reverberar ao simples deslocamento da velocidade para a lentidão. Da velocidade para a ação de desacelerar. Do tiquetaquear do relógio ao escorregar da areia da ampulheta. De passo em passo, primeiramente, escolhemos nosso ritmo, um tempo giusto, encontrando nosso próprio andamento. Embora possamos nos deparar com o paradoxo de que "Devagar nem sempre quer dizer devagar" (HONORÉ, 2005, p.26), é importante rastrear os usos que praticamos da palavra devagar, pois a ideia de desaceleração para o mundo capitalista é um xingamento. A palavra 'devagar' apresenta um sentido negativo, que significa ser lento, ruim, improdutivo e preguiçoso. Algo que nem de longe você colocaria no seu currículo (Honoré, 2005). Eis um jogo de palavras, um currículo (escolar) que produz sujeito a serviço da produtividade.

Trata-se, ao contrário, de uma 'contraconduta', um modo outro de condução, que resiste às armadilhas criadas pela velocidade, pelo sentimento da falta de tempo, pela valorização da pressa e escassez do tempo. Trata-se de governar o tempo e não ser governado por ele. "É uma questão de explorar o mundo e a reação que se tem diante dele, no ritmo de cada um" (HONORÉ, 2005, p.300). Ou ainda, conduzir a vida com uma velocidade certa: "Às vezes depressa. Às vezes devagar. Às vezes nem uma coisa nem outra. Viver Devagar significa nunca se afobar, nunca tentar ganhar tempo só para ganhar tempo" (ibidem, p.309). Isso implica afirmar que a resistência exige coragem de desafiar o próprio tempo em nossas práticas cotidianas (escolares), visto que "a desaceleração continua sendo 
uma luta até que consigamos rever radicalmente as regras que governam quase todas as esferas da vida: a economia, o trabalho, o urbanismo, a educação, a medicina" (HONORÉ, 2005, p.313).

Esse contraponto insere-se tanto em nossas vidas quanto nas vidas escolares, pois a relação que temos com o tempo é muito próxima. Carl Honoré (2005) comenta alguns fatos que mostram a relação temporal presente nas escolas, a saber: as crianças não nascem obcecadas pela velocidade e produtividade - nós [adultos] é que as fazemos assim; na escola, aprendem a viver olhando o relógio e a empregar o tempo de maneira mais eficiente possível; os pais reforçam a tendência criando uma agenda de atividades extracurriculares para seus filhos; a escola como campo de batalha, para ser o primeiro da turma, rumo à aprovação nos exames; horários rígidos que obrigavam os alunos a ficar saltando de uma matéria [disciplina] a outra ao sabor do relógio. Esses fatos, que não pretendem a generalização de um contexto, mas pontos de contato entre diferentes situações escolares, permitem que o modo como o currículo e a estrutura escolar são organizadoa em seu funcionamento seja problematizado.

Maurice Holt apresenta uma problematização sobre as políticas curriculares e a promoção do conceito de slow school (escola desacelerada) em combate à "camisa de força curricular" presente na América do Norte e Grã-Bretanha ao gerar visibilidade para o "modelo hambúrguer de educação". Em seu livro The common curriculum: its structure and style in the comprehensive school (1978), descreve a importância de um currículo abrangente que permite que a escolha seja feita entre grupos de matérias com diferentes estratégias de ensino, em vez de disciplinas isoladas. A ideia de slow school não significa ler em velocidade reduzida para pessoas vagarosas, mas trata de filosofia, tradição, comunidade e escolhas morais. O aluno tem tempo (HOLT, 2006). Na slow school, "o aluno aprende um pouco de teoria sobre o que ele quer fazer, mas esse conhecimento está inserido na prática e é o que dá vida à prática (...). A teoria da fast school é também simples: educar é avaliar o desempenho em conteúdos específicos" (ibidem, p.91).

As pistas fornecidas por Holt (2006) é que a escola pode ser comparada às vivências modernas do fast-food, pautada em padrões que oferece um cardápio rápido de conteúdos e procedimentos. Ao contrário, a slow school é uma narrativa cuja ênfase está em seu processo. A provocação presente no título de seu artigo It's time to start the Slow School Movement (É hora de começar o Movimento Slow School - 2002) indica possibilidades de caminhos a trilhar. Isso nos ajuda a re-pensar nossas relações temporais e espaciais que temos praticados na prática cultural (escolar) e como poderíamos evitar que diferentes tempos e espaços que habitam a escola não sejam ou se reduzam a repetição do Mesmo. Fato este que implica na condição de existência de diferentes conexões que privilegiem a politicidade do conhecimento e a vida do tempo que pulsa em nós.

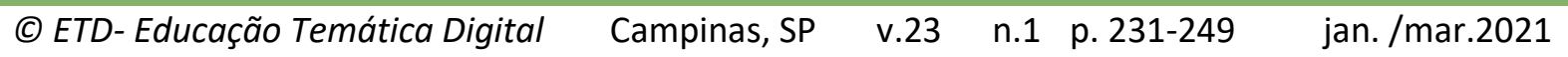




\section{ENCENAÇÕES POSSÍVEIS...}

Diante do jogo de cenas apresentado, que suspende os automatismos das relações temporais e espaciais presentes nas formas de vida escolares, continuamos interrogando e investigando pelos tempos que escapam, demoram, desaceleram e que devolvem a vida do tempo escolar. E, ainda, pelo alisamento do espaço como condições de possibilidade para a proliferação de processos de subjetivação outros que se tornem livres de si mesmo. Talvez seja intervir pela re-existência das formas de vida escolares na pulsão de um próprio tempo de vida (escolar) que opere pela via do bem comum, democrática e pública.

Assim sendo, consideramos que a Etnomatemática, nessa perspectiva de contraconduta, pode potencializar caminhos para evidenciar os silêncios e tecer gramáticas do tempo, possibilitando brechas, fissuras, lutas, combates e resistências a um currículo único, rígido e universal. Ou ainda, fazer pulsar um currículo com tempos e espaços que não são focados nem na produção e nem na necessidade dos indivíduos, mas que permite experiências que elevam os sujeitos para além do seu mundo imediato e enfatizam a capacidade da emergência de novos mundos. Um currículo movente, acentrado e plural. Isso implica em novos olhares e ações para o currículo de matemáticas, no plural, pois a própria matemática acadêmica e a matemática escolar são colocadas em suspeição ao considerarmos a co-presença de práticas culturais que apresentam outras formas de pensar não disciplinar.

O desejo é que, de passo em passo, possamos encontrar o tempo giusto para a Educação Matemática (escolar) e, de modo amplo, para a Educação, criar um currículo devagar na vitalidade de seus próprios andamentos. Devagar não sendo necessariamente devagar, ou melhor, prolongar o presente vivido de modo que as coisas aconteçam em seu próprio tempo, cuja prática de si está em saber quando se deve ir mais rápido ou devagar. Um modo de estar no mundo, de pensar, de olhar e de viver as experiências em sua intensidade nos diferentes campos da atividade humana.

\section{REFERÊNCIAS}

ARTIÈRES, Philippe. Dizer a atualidade - o trabalho de diagnóstico em Michel Foucault. In: GROS, Frédéric (Org.). Foucault: a coragem da verdade. São Paulo: Parábola. p.15-37, 2004.

BELLO, Samuel Edmundo Lopez. Jogos de linguagem, práticas discursivas e produção de verdade: contribuições para a educação (matemática) contemporânea. Revista ZETETIKÉ, v.18, p. 545-588, 2010. 
BELLO, Samuel Edmundo Lopez; LONGO, Fernanda. Etnomatemática: uma analítica discursiva dos seus enunciados. ENCONTRO NACIONAL DE EDUCAÇÃO MATEMÁTICA ENEM, 10., Salvador, 2010. Anais do...Salvador, 2010. p. 1-11.

CARVALHO, Juciara Guimarães. "O mar está pra peixe": tempo e espaço em jogos de linguagem matemáticos de pescadores artesanais. Dissertação (Mestrado em Educação Científica e Tecnológica) - Universidade Federal de Santa Catarina, Florianópolis: UFSC, 2016.

FOUCAULT, Michel. Arqueologia das ciências e história dos sistemas de pensamento. Ditos e Escritos II. Rio de Janeiro: Florense, 2005.

FOUCAULT, Michel. Vigiar e punir: nascimento da prisão. Tradução de Raquel Ramalhete. Petrópolis: Vozes, 2007.

FOUCAULT, Michel. Segurança, território e população. São Paulo: Martins Fontes, 2008.

FOUCAULT, Michel. A hermenêutica do sujeito: curso dado no Collège de France (19811982). São Paulo: Editora WMF Martins Fontes, 2010.

FOUCAULT, Michel. Conferência 5. A verdade e as formas jurídicas. Tradução Eduardo Jardim e Roberto Machado. Rio de Janeiro: Nau, p. 103-123, 2013.

FOUCAULT, Michel. A sociedade punitiva: curso no Collège de France (1972-1973). Trad. Ivone Benedetti. São Paulo: Editora WMF; Martins Fontes, 2015.

GILLOT, Pascale; LORENZINI, Daniele (orgs). Foucault/Wittgenstein: subjectivité, politique, éthique. Paris, France: CNRS Éditions, 2016.

GROS, Frédéric. A parrhesia em Foucault (1982-1984). In: GROS, Frédéric (Org.). Foucault: a coragem da verdade. São Paulo: Parábola Editorial, p.155-166, 2004.

GROS, Frédéric ; DAVIDSON, Arnold. (Org.) Foucault, Wittgenstein: de possibles rencontres. Paris, France: Éditions Kimé, 2011.

HOLT, Maurice. It's time to start the slow school movement. Phi Delta Kappan, v. 84, n.4, 264-271, 2002.

HOLT, Maurice. A ideia da slow school: é hora de desacelerar a educação? In: STONE, M.K.; BARLOW, Z. (Org.). Alfabetização ecológica: a educação das crianças para um mundo sustentável. Tradução de Carmen Fischer. São Paulo: Cultrix, p. 87-94, 2006.

HONORÉ, Carl. Devagar. Tradução de Clóvis Marques. Rio de Janeiro: 2005.

KNIJNIK, Gelsa; WANDERER, Fernanda; GIONGO, leda Maria; DUARTE, Claudia Glavam.

Etnomatemática em movimento. Belo Horizonte: Autêntica, 2012.

(C) ETD-Educação Temática Digital Campinas, SP $\quad$ v.23 $\quad$ n.1 $\quad$ p. 231-249 jan./mar.2021 
MASSCHELEIN, Jan; SIMONS, Maarten. Em defesa da escola: uma questão pública. Belo Horizonte: Autêntica, 2013.

MIGUEL, Antonio. A terapia gramatical-desconstrucionista como atitude de pesquisa (historiográfica) em educação (matemática). Revista Perspectivas da Educação Matemática - UFMS, v.8, p. 607-647, 2015.

MIGUEL, Antonio.; VILELA, Denise Silva.; MOURA, Ana Regina Lanner de. Problematização indisciplinar de uma prática cultural numa perspectiva wittgensteiniana. Revista Reflexão e Ação. Santa Cruz do Sul, v.20, n.2, p.06-31, 2012.

MONTEIRO, Alexandrina; MENDES, Jackeline Rodrigues. A etnomatemática no encontro entre práticas e saberes: convergências, tensões e negociação de sentidos. Revista Latinoamericana de Etnomatemática, v.7, n.3, p. 55-70, 2014.

MONTEIRO, Alexandrina; MENDES, Jackeline Rodrigues. Etnomatemática como Movimento de Contraconduta na Mobilização de Saberes em Práticas Culturais. SEMINÁRIO INTERNACIONAL DE PESQUISA EM EDUCAÇÃO MATEMÁTICA - SIPEM, 6., Pirenópolis, 2015. Anais do...Pirenópolis, GO, 2015, p.1-11.

MONTEIRO, Alexandrina; MENDES, Jackeline Rodrigues. Saberes em práticas culturais: condutas e contracondutas no campo da Matemática e da Educação Matemática. Periódico Horizontes, USF. Itatiba, p. 1-14, 2019.

REVEL, Judith. O pensamento vertical - uma ética da problematização. In: GROS, Frédéric (Org.). Foucault: a coragem da verdade. Tradução de Marcos Marcionilo. São Paulo: Parábola Editorial, p.65-87, 2004.

SÊNECA, Lúcio Aneu. Cartas à Lucílio. Tradução de J. A. Segurado e Campos. Lisboa: Fundação Calouste Gulbenkian, 1991.

VEIGA-NETO, Alfredo. De geometrias, currículo e diferenças. Educação \& Sociedade, v.79, n.23, p.163-186, 2002.

VEIGA-NETO, Alfredo. Foucault e a educação. Belo Horizonte: Autêntica, 2011.

WITTGENSTEIN, L. Investigações filosóficas. Tradução de Marcos G. Montagnoli. Petrópolis, RJ: Vozes, 2014.

Revisão gramatical realizada por:

Alessandra Gomes Varisco.

E-mail: alevariscorevisora@gmail.com 